\title{
RadiologieKongressRuhr zeigt sich interdisziplinär und interaktiv
}

Ob Fit für den Facharzt-Kurs oder interdisziplinärer Austausch mit Orthopäden: Der 12. RadiologieKongressRuhr (RKR) bot zwei Tage lang radiologische Vielfalt für die Fort- und Weiterbildung. Vom 7. bis 8. November trafen sich Radiologinnen und Radiologen, MTRA, Medizinphysikerinnen und Medizinphysiker sowie Industriepartner im Kongresszentrum Westfalenhallen Dortmund. Mit 1326 Gästen war der Fachkongress gut besucht.

Zwei erfolgreiche Premieren hatte der RKR in diesem Jahr zu bieten. Erstmalig konnten Interessierte in Simulatorenkursen radiologische Interventionen unter fachkundiger Anleitung ausprobieren. Und im neuen Programmformat „Meine schönsten Fehler“ berichteten Experten ganz offen von den Fällen, bei denen nicht alles glatt lief - um sie anschließend mit den Teilnehmenden zu diskutieren. Auch darüber hinaus stand der Kongress ganz im Zeichen der Interaktion: In vielen Sessions konnten die Teilnehmenden sich per TED-Umfragen aktiv beteiligen und ihr Wissen testen. Von den Grundlagen bis zum Experten-Know-how war das Wissen kompakt in organbezogenen Themenblöcken strukturiert. „Mit dem 12. RKR haben wir die Basis für ein curricular strukturiertes Fort- und Weiterbildungsprogramm gelegt, an das wir mit den künftigen Kongressen nahtlos anknüpfen werden“, blickt Kongresspräsident Prof. Dr. Stefan Rohde in die Zukunft.

Unter der Schirmherrschaft der Deutschen Röntgengesellschaft und der Rheinisch-Westfälischen Röntgengesellschaft war der Kongress inzwischen zum zweiten Mal im großzügigen Kongresszentrum Westfalenhallen in Dortmund zu Gast. Als Standort mit kurzen Wegen bietet es gleichzeitig Raum für die Veranstaltungen aller radiologischen Berufsgruppen. So widmete sich der RKR-Donnerstag ganz dem MTRA-Nachwuchs. Schülerinnen und Schüler präsentierten spannende Themen, von Bodypacking bis zum Cyberknife. Erfahrene MTRA konnten ihr Wissen u. a. in der Kinderradiologie und sich über Dosismanagement im Rahmen des neuen Strahlenschutzgesetzes informieren.
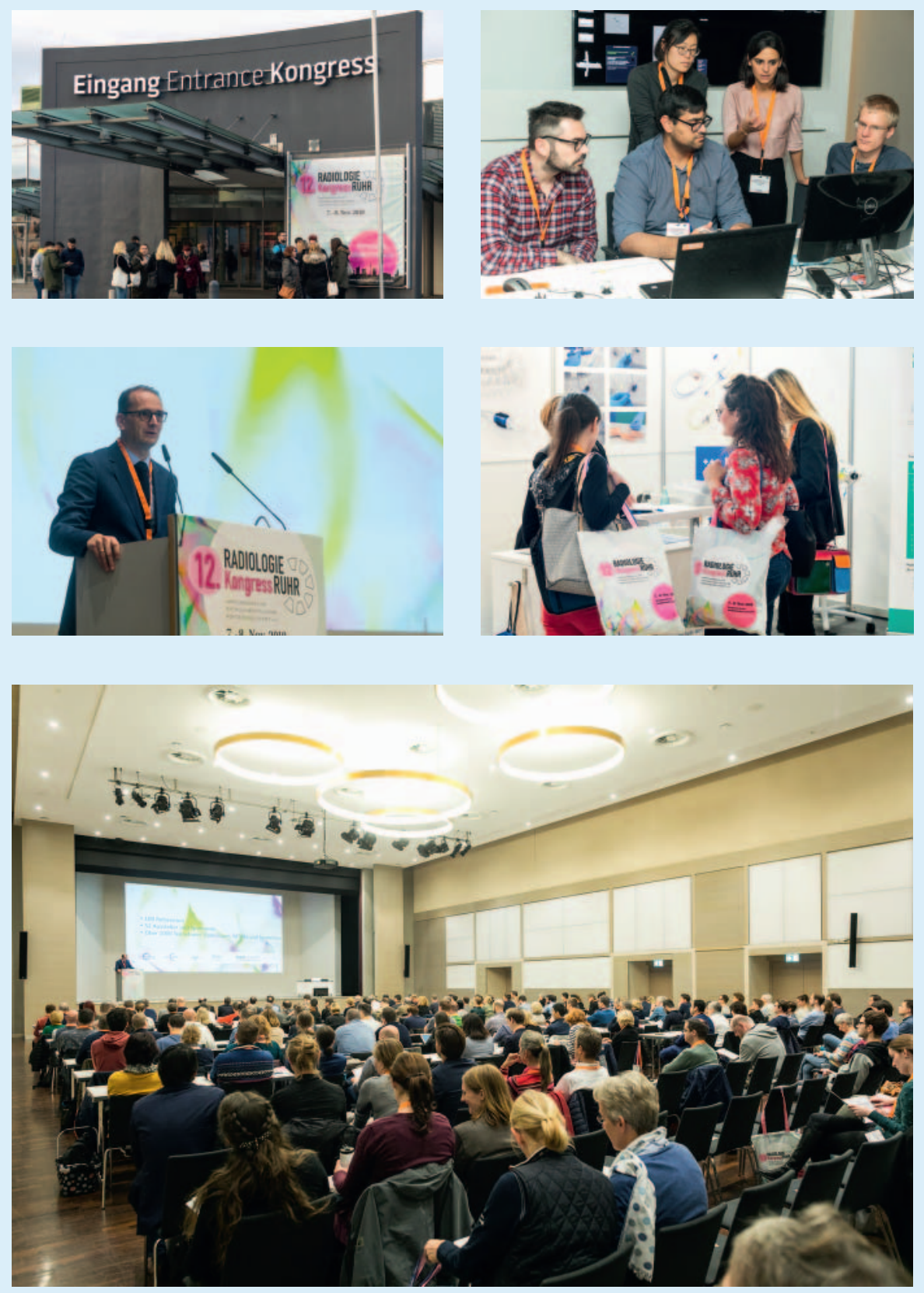

Rund um das fachliche Programm gab es zahlreiche Gelegenheiten, sich mit Kolleginnen und Kollegen über das neugewonnene Wissen auszutauschen und neue Kontakte zu knüpfen. Nicht zuletzt erwies sich das neu etablierte abendliche „Wintergrillen" als Chance zum Networking in entspannter Atmosphäre.

\section{Save the Date: RKR 2020}

Von Diagnostik bis Therapie - Sie möchten sich auch im kommenden Jahr wieder in der Region umfassend weiterbilden? Dann notieren Sie sich schon einmal den 5 . bis 6 . November 2020! Wir würden uns freuen, Sie zum 13. RadiologieKongressRuhr in den Westfalenhallen Dortmund begrüßen zu dürfen. 